\title{
XIX. On the electricity of minerals
}

\section{Hauy}

To cite this article: M. Hauy (1811) XIX. On the electricity of minerals, Philosophical Magazine Series 1, 38:160, 81-85, DOI: 10.1080/14786441108638608

To link to this article: http://dx.doi.org/10.1080/14786441108638608

曲 Published online: 27 Jul 2009.

Submit your article to this journal

Џ Article views: 2

Q View related articles $₫$ 


\section{On the Electricity of Minerals. By M. HAUY*.}

$\mathrm{T}$ - property which certain natural bodies possess of becoming electrical by the intermedium of heat, furnishes mineralogy with one of the most advantagenus characters for ascertaining what they are, and also gives rise to experiments which are interesting, in so far as they serve to manifest a remarkable co-relation between the crystalline forms of the same bolies and the pusitions of their electrical poles. But these experiments are at the same time delicate, particularly when we employ crystals of boiated magnesia, which, with a rolume scarcely exceeding two or three millimeties, have eight poles opposite to each other, in pairs; the powers of which have little ener.ry, and reside each in a single point. Previously to the publication of my Treatise on Mineralogy, 1 was accupied with the construction of an apparatus which should be at the same time convenient, and sufficiently sensible to leave no donbt as to the results of the experiments in question. That which I have described in my Treatise, tome $i$. and in which I afterwards made a change as subsequently described in a former volume of these Annals, would appear to be perfect in every respect, if its effects were not subject, like those of all electrical machines, to be affected by the state of the atmosphere. I shall briefly mention here, that this apparatus consists of a small needle (Pl. III. fig. 1.) of copper or silver, terminated by two globules, moveable on a pivot, and isolated, to which we give at pleasure the vitreous or resinous electricity, by the action exercised upon it by an idio-electrical body to which friction has communicated the contrary electricity. If this body is a stick of wax, for instance, we present it at a few centimetres distance from the stalk which supports the small needle, at the same time that we keep a finger applied to the foot $a$ of this stalk: we afterwards remove the finger, then the stick of wax, and in this case the apparatus is vitreously electrified. Now, when the air is loaded with aqueous vapours, its influence on the metallic needle destroys in an instant the electrical virtues of the latter, or renders it so feeble and fugacious, that the operator is compelled to abandon the experiment, and to wait for dry weather. In a public lecture-room, a numerous audience produces a similar effect to that of dampness. I have on such occasions tried in vain to electrify by friction

* Ann. du Museum d'Histoire Naturelle, tome xr.p. 1.

Vol. 38. No, 160, August 1811. F astick 
Fig. 5.

Fig. 3.

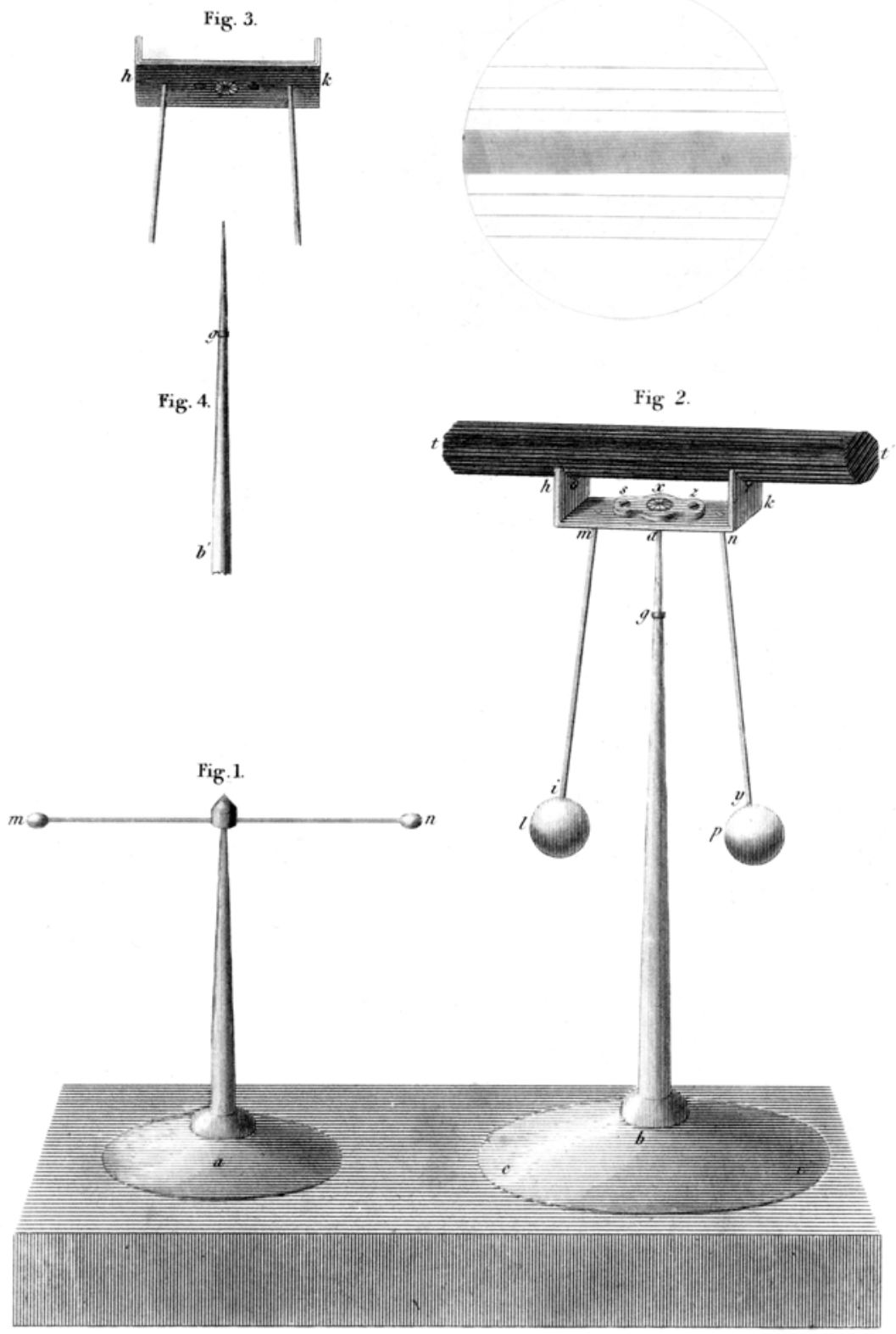


a stick of wax or gum lac, particularly in the great heats of summer.

These inconveniences suggested the idea of employing in the experiments relative to the ohject in question, only bodies susceptible of being electrified by heat, and to make their mutual capacities subservient to the development of their properties. As the two fluids which compose the natural electric fluid of these bodies, before the experiment, remain engaged in their pores; after being extricated by the effects of heat, they are removed from all external influence, and the electrical state of the bodies is kept up in the midst of the dampest air. I do not know if there is not even something more striking in those experiments which connect the functions of budies electrical by heat, with those of the magnet, to which they have so great an analogy, either in consequence of their double polar virtue, or by the law to which the distribution of the two fluids is stbjected in their interior.

I shall now describe the new apparatus which I employ in the experiments in question, and which was made with much care by $\mathbf{M}$. Tavernier, an eminent watch-maker. It is composed of two principal pieces; the one is a stalk of silver, $a b$ (fig. 2.) fixed on a round piece of the same metal, and having at its upper extremity a very sharp-pointed stcel needle, $a g$ : the other piece consists principally of a rectangular plate of silver, $h k$, turned up at both ends, where holes have been made at $o r$. This silver plate is pierced in the middle by a circular hole, in order to receive a small cover of rock crystal which is held by a circle of silver, and by means of two screws, $s, z$.

Towards the extremities of the inferior surface of the plate $h k$, are fixed two silver wires $m i, n y$, directed a little obliquely to this surface, and terminated by two globules $l, p$ of the same metal. Fig. 3 . represents this plate seen from below, and fig. 4. represents the stalk, with the steel needle by which it is terminated.

When the apparatus is fixed, as we see in fig. 2, the needle in question performs the office of a pivot, which en. ters into a small aperture made in the under surface of the rock crystal cover. The two boles $o, r$, are destined to receive a tourmaline $t t^{\prime}$, or any other body of an oblong form, susceptible of being electrized by heat; and such is the seusibility of the apparatus, that a small force which acts by attraction, or by repulsion, on either extremity of the body $t t^{\prime}$, instantly produces a very perceptible rotatory motion in this body. 
To proceed to the experiments: let us suppose in the first place that we wish to determine the positions of the electrical poles of a tourmaline, which is of a thin and oblong form, like all the tourmalines of Spain. After baving heated it, we shall place it in the apparatus, and present successively, at a small distance from its two extremities, another body which has been electrized by friction. I piefer employing for this purpose the Saxon or Brazil topazes, because these minerals, as I have remarked in my Treatise on Mineralogy, are extremely sensible to the action of friction in order to excite the electrical virtue in them, so that not only a dainp atmosphere does not hinder them from acquiring it, but they preserve it for a considerable time. The kind of electricity in question being of the same nature with that of glass, the pole of the tourmaline which the tonaz will repel will be the virreous pole, and that upon which it will act by attraction will be the resinous pole. It is sufficient to have a tourmaline susceptible by its form of being placed in the apparatus, and the poles of which are known, in order that it may serve as a term of comparison to all the bodies of the same species, or of different species, which share the property in question, whatever in other respects are the forms and dimeusions of such bodies. After having heated that which we wish to examine, we bring it successively by its two extremities near both of those of the tourmaline, and the consequence of the result is presented of itself, agreeably to the principle common to electricity and to magnetism, viz. the pole solicited by homogeneous fluids is repelled, and those in which heterogeneous fluids reside are attracted.

The advantages of the appraratus which I have described, are particularly felt in the experiments relative to borated magnesia, which, in order to succesd, require very favourable circumstances, when we use the metallic needle which I first mentioned. It is necessary that we should wait until the action of the tourmaline placed in the apparatus has been diminisbed, by cooling, to the point of being found in proportion to the feeble virtue of the crystal of borated magnesia; and we must also take care to keep the crystal in such a position, that, the axis which passes by the pole which we present to the tourmaline being perpendicular to the length of the latter, the same pole corresponds to the centre of action of the tourmaline, which we know to be very near the extremity.

This apparatus may be aiso employed for determining the kind of electricity which a body acquires by means of fric$\mathrm{F} 2$ tion. 
tion. If it repels the pole of the tourmaline to which we first present it, this only indicates that the body is itself in the electric state, and also that its electricity is contrary to that of the pole in question. Put if the tourmaline was attracted, we could conclude notbing from it, because a body which is even in the natural state, acts always by attraction on an electrized body, whatever be the kind of electricity which this last requires. In this case, therefore, we must afterwards present the body to the other pole of the tourmaline; and if the repulsion succeeds the attraction; we shall have a proof that this body is in a state opposite to that of the pole which has been repelled.

When we employ the electricity acquired by heat, solely as a mineralogical character, the small metallic needle represented (fig. 1.) is sufficient for the cxperiments relative to this character, without its being even necessary to isolate this needle. We judge that a mineral is endowed with the property in question, according as it attracts the needle to it, or leaves it fixed when placed at a small distance from it.

1 recently made use of this method for comparing various minerals, relative to the faculty which they have of preserving for a longer or shorter time the electricity acquired by friction. After baving put them in the electrical state, I placed them on any stone, (marble for instance,) so as to make the surface which had been rubbed, opposite to that which lay upon the stone, and from time to time I took them with my fingers or with pincers, by a corner which was far from the electrized part, in order to present them to the small needle. The topaz, of all the minerals which I tried, seemed to preserve electricity longest. A cut piece of the limpid Brazil kind acted upon the needle at the end of 32 hours. In the hyaline corindon, called oriental sapphive, the emerald, the spinel, and other stones which are made into trinkets, the duration of the electrical virtue generally exceeded five or six hours : it exceeded 24 hours in an emerald from Peru. But I met with two minerals which differ from the above in a striking manner by a less coercive force with respect to the electrical fluid,-the one is the diamond and the other rock crystal, - and I remarked that their electrical virtne was extinct in 15 or 20 minutes. Some crystals of quartz, however, preserved it for about 40 minutes.

The limpid Brazil topaz, already mentioned, seems to resemble the diamond in the liveliness of its lustre, where it has been cut. It is the same with the hyatine corindon called white sapphire. The foregoing results might be em- 
ployed in such cases, at least as auxiliary characters, to assist us in listnguishing substances which are so different in their nature.

Coliured glass possesses but frebly the faculty of preserving electricity; and if there does not exist in this respect any very marked difference between such substances and quartz, we shall at least avoid confounding with the ererald, the topaz, or the sapphire, factitious stones which sometimes present imposing imitations of these gems. I know that the specific gravity, the hardness, and the refraction of these substances present much more palpable means of detection than the above; but we cannot too much multiply indications which may assist us in ascertaining a mineral substaxice, when the artist has stripped it of the exterior which nature had given it, or rather of that form which cannot be imitated by any other.

XX. Experiments and Observations on the different Modes in which Death is produced by certuin vegetalle Poisons. By B. C. Brodie, Esq.F.R.S. Communicated by the Sociely for promoting the Knowledge of Animal Chemistry*.

I. The following experiments were instituted with a view to ascertain, in what manner certain substances act on the animal system, so as to nccasion death, independently of mechanical injury. I was led to the inquiry, from the subject of it appearing to be of cousiderable interest and importance, and from a hope, that, in the present improved state of physiological knowledge, we might be enabled to arrive at some more satisfactory conclusions than had been deduced from any former observations.

The substances which act as poisons when applied to the animal body are very numerous. In the experiments which I have hitherto made, I have employed vegetable poisons only. Of these I have selected such as are very active and certain in producing their effects, believing that, on this account, the exact nature of those effects woutd be more readily ascertained. The principal objects which I have kept in view have been to determine, on which of the vital organs the poison employed exercises its primary influence, and through what medium that organ becomes affected. I have also endeavoured to ascertain by what means the fatal consequences of some poisons may be pre-

* From the Philosophical Transactions for 1811, part i. 